\title{
Numerical simulation of drifting snow: erosion and deposition models
}

\author{
Mohamed Naaim, ${ }^{1}$ Florence Naaim-Bouvet, ${ }^{1}$ Hugo Martinez ${ }^{2}$ \\ ${ }^{1}$ Snow Engineering and Avalanche Control Division, CEMAGREF, BP 76, 38402 Saint-Martin-d'Hères Cedex, France \\ ${ }^{2}$ Ianigla, CONICET, CC 330, 5500 Mendoza, Argentina
}

\begin{abstract}
Earlier works on numerical modelling are analysed. Anderson and Haff (1991) proposed a model using the "splash" function which was defined for cohesionless sand. The Uematsu and others $(1989,1991)$ and Liston and others (1993, 1994) approaches are based on fluid-mechanics conservation laws where the snow is transported and diffused by the air flow. These models consider the saltation layer as a boundary condition.

For the flow, and for the suspension, we adopt the same model as that of Uematsu and Liston. For mass exchange between the flow and snow surface, we have developed an erosion-deposition model where mass exchange is defined in relation to flow turbulence, threshold-friction velocity and snow concentration. Our snow-erosion model was calibrated using Takeuchi's (1980) field measurements. The deposition model was tested by comparing numerical results with wind-tunnel ones, for sawdust-accumulation windward and leeward of a solid snow fence with a bottom gap. The numerical results obtained are close to the experimental results. The main results of the various sensitivity experiments are: the leeward accumulation is very sensitive to the ratio $\left(u_{*} / u_{* t}\right)$ (it appears for $\left(u_{*} / u_{* \mathrm{t}}\right)$ close to 1 and disappears for $\left.\left(u_{*} / u_{* \mathrm{t}}\right)>1.2\right)$, the global accumulation produced by the fence increases as $\left(u_{*} / u_{* \mathrm{t}}\right)$ decreases and the back reaction of particles on turbulence extends slightly the windward accumulation.
\end{abstract}

\section{NOTATION}

$u_{8} \quad$ Friction velocity $\left(\mathrm{m} \mathrm{s}^{-1}\right)$

$u_{* r} \quad$ Real friction velocity, corresponding to the friction velocity modified by the presence of snow particles $\left(\mathrm{m} \mathrm{s}^{-1}\right)$

$u_{* t} \quad$ Threshold friction velocity $\left(\mathrm{m} \mathrm{s}^{-1}\right)$

$U_{\mathrm{F}} \quad$ Particle-settling velocity $\left(\mathrm{m} \mathrm{s}^{-1}\right)$

$(\bar{u}, \bar{v})$ Mean velocity components in the $x(\mathrm{~m})$ (horizontal) and $y(\mathrm{~m})$ (vertical) directions $\left(\mathrm{m} \mathrm{s}^{-1}\right)$

$u_{\mathrm{i}} \quad$ Mean velocity component in the $O x_{\mathrm{i}}$ direction $\left(\mathrm{m} \mathrm{s}^{-1}\right)$

$z_{0}^{\prime} \quad$ Aerodynamic roughness height $(\mathrm{m})$

$D_{\mathrm{p}} \quad$ Particle diameter $(\mathrm{m})$

$V_{\mathrm{p}} \quad$ Particle volume $\left(\mathrm{m}^{3}\right)$

$\sigma_{\mathrm{s}} \quad$ Turbulent Schmidt number

$\rho \quad$ Air density $\left(\mathrm{kg} \mathrm{m}^{-3}\right)$

$\sigma \quad$ Particle density $\left(\mathrm{kg} \mathrm{m}^{-3}\right)$

$\gamma \quad$ Bulk density of the snow $\left(\mathrm{kg} \mathrm{m}^{-3}\right.$

$g \quad$ Gravitational acceleration $\left(\mathrm{m} \mathrm{s}^{-2}\right)$

K Von Kármán's constant

$h \quad$ Surface level $(\mathrm{m})$

$t$ Time (s)

$p \quad$ Pressure $\left(\mathrm{N} \mathrm{m}^{-2}\right)$

$\bar{C} \quad$ Particle concentration $\left(\mathrm{kg} \mathrm{m}^{-3}\right)$

$C_{\mathrm{s}} \quad$ Particle concentration in the saltation layer $\left(\mathrm{kg} \mathrm{m}^{-3}\right)$

$C_{\max }$ Maximum particle concentration in the saltation layer $\left(\mathrm{kg} \mathrm{m}^{-3}\right)$

$v_{\mathrm{t}} \quad$ Turbulent viscosity coefficient $\left(\mathrm{m} \mathrm{s}^{-1}\right)$

$\varphi_{\mathrm{g}} \quad$ Erosion or deposition flux $\left(\mathrm{kg} \mathrm{m}^{-2} \mathrm{~s}^{-1}\right)$

$\varphi_{\mathrm{s}} \quad$ Mass flux between the suspension and the saltation layers $\left(\mathrm{kg} \mathrm{m}^{-2} \mathrm{~s}^{-1}\right)$
$Q_{\text {s }} \quad$ Total mass-transport rate per unit of lateral dimension in the saltation layer $\left(\mathrm{kg} \mathrm{m}^{-1} \mathrm{~s}^{-1}\right)$

$Q_{\mathrm{t}} \quad$ Total mass-transport rate per unit of lateral dimension in the suspension layer $\left(\mathrm{kg} \mathrm{m}^{-1} \mathrm{~s}^{-1}\right)$

$h_{\mathrm{s}} \quad$ Height of the saltation layer $(\mathrm{m})$

$k \quad$ Turbulent kinetic energy $\left(\mathrm{m}^{2} \mathrm{~s}^{-2}\right)$

$\epsilon \quad$ Dissipation of the turbulent kinetic energy $\left(\mathrm{m}^{2} \mathrm{~s}^{-3}\right)$

\section{INTRODUCTION}

In high mountain areas, blowing snow produces cornices creating dangerous avalanche-starting zones. In other areas, blowing snow reduces visibility and creates snowdrifts. Drifting snow poses economic problems, especially for roads and railways. Taking snowdrift formation into account is therefore a necessity both in terms of predicting and controlling drift patterns. However, it is time-consuming and often unrealistic to study full-scale snowdrifts in the field. Physical modelling, carried out in wind-tunnels since the 1930s, allows one to study the formation of small-scale snowdrifts but raises a difficult problem: all similitude requirements cannot be satisfied simultaneously. Therefore, we have in recent years turned to numerical modelling. As an introduction, we give a brief, non-exhaustive review of computer modelling of aeolian transport before introducing our own approach.

\section{THE EXISTING NUMERICAL MODELS}

Two categories of multiphase flow theories can be used for modelling drifting snow: the Eulerian multiphase flow 
model and the Lagrangian particle model. The Eulerian multiphase flow model can be simplified by treating the particles as a continuum field and by using a convectiondiffusion equation for particle concentration. We present later an example of each type of model.

\section{Drifting-snow models of Uematsu and others and Liston and others $(1993,1994)$} (1989)

This kind of model was first developed by Uematsu and others (1989) and followed by Liston and others (1993). It is based on two-dimensional time-averaged Navier-Stokes equations and a modified $k-\epsilon$ turbulence model proposed by Chen and Wood (1985). These equations allow one to obtain the turbulent-flow field, the turbulent kinetic energy and the kinetic-energy dissipation.

Concerning snow transport, Liston and others (1993) took the saltation process into account and treated snowdrifting using the following total mass-transport rate per unit of lateral dimension:

$$
Q_{\mathrm{s}}(x)=C \frac{\rho}{g} \frac{U_{\mathrm{F}}}{u_{* \mathrm{t}}} u_{*}(x)\left(u_{*}(x)-u_{* \mathrm{t}}\right)
$$

where $C$ is a constant.

Afterwards, Liston and others (1994) introduced the diffusion process using the particle mass-concentration equation which takes the following form in the turbulentdiffusion layer:

$$
\begin{aligned}
\frac{\partial \bar{C}}{\partial t}+\bar{u} \frac{\partial \bar{C}}{\partial x} & +\left(\bar{v}-\left|U_{\mathrm{F}}\right| \frac{\partial \bar{C}}{\partial y}\right. \\
& =\frac{\partial}{\partial x}\left(\frac{v_{\mathrm{t}}}{\sigma_{\mathrm{s}}} \frac{\partial \bar{C}}{\partial x}\right)+\frac{\partial}{\partial y}\left(\frac{v_{\mathrm{t}}}{\sigma_{\mathrm{s}}} \frac{\partial \bar{C}}{\partial y}\right) .
\end{aligned}
$$

The concentration at the bottom of the suspension layer is the mean concentration in the saltation layer. Changes in the snow-surface level are described by the vertically integrated mass-continuity equation:

$$
\frac{\partial h(x, t)}{\partial t}+\frac{1}{\gamma} \partial\left(\frac{Q_{\mathrm{t}}(x, t)+Q_{\mathrm{s}}(x, t)}{\partial x}\right)=0 .
$$

Snow deposition is computed assuming that snow accumulates where shear velocity falls below the threshold shear velocity. The control volumes are filled one by one. When a control volume is filled with snow, the flow field (which depends on the surface topography) is recomputed and the same process is repeated until the accumulated snowdrift reaches an equilibrium profile. Liston and others (1994) considered implicitly that the mass-transport rate $Q_{\mathrm{s}}$ reacts instantaneously to a change in friction velocity (Equation (1)). So, this numerical model does not take the inertia of snow erosion and snow deposition into account. In fact, drift-particle saturation is not reached immediately when the wind-friction speed increases, and deposition occurs progressively when the wind-friction speed decreases.

If this model makes it possible to compute snowdrifting at equilibrium, it does not estimate the time required to obtain a given snow accumulation and variations in snowdrift formation. For example, the windward and leeward drift generated by a solid fence are forming simultaneously. This result is opposite to the results obtained by the numerical simulation of Liston and others (1994).

\section{Drifting-sand model of Anderson and Haff (1991)}

sand deposition is taken into account in the model proposed by Anderson and Haff (1991). This numerical model, developed for the reptation and the saltation in a turbulent boundary layer over a flat area, is based on the "splash" function. The "splash" function, generated from physical and numerical experiments, allows one to formulate statistically grainbed interaction: the "splash" function returns the number of ejected particles, the probability distribution of their ejection velocities and the velocities of the rebounding grains.

Encouraging results are obtained using the "splash" function for sand drift (Anderson and Haff, 1991). However, this model is not suitable for snow and turbulent separated flows over obstructions without modification.

First, it is necessary to introduce suspension. But Anderson and Haff (1991) considered that it is possible to use the continuum theory far from the bed. In addition, this model cannot be applied in the case of a turbulent separated flow over obstructions: the estimations of "grain stress" and trajectory times are no longer valid. Lastly, it has appeared that the "splash" function defined for sand particles differs from that defined for snow particles because of the shape and the cohesion of the snow particles (Naaim-Bouvet, 1997).

\section{NUMERICAL SIMULATION OF SNOWDRIFTING}

Although the numerical model proposed by Anderson and Haff is physically more sound, it is currently difficult to adapt it to snow particles because of the lack of knowledge about the "splash" function. In the present state of our knowledge, we do not have any idea of the form taken by the "splash" function for different types of snow. We therefore propose a numerical simulation based on the continuum theory and taking into account inertia of snow erosion and snow deposition by means of erosion and deposition fluxes. We also use the modified $k-\epsilon$ model proposed by Chen and Wood (1985) to close this system of equations.

\section{Governing equations}

The model is based on the mass-conservation laws for both the fluid and the particles, the conservation of momentum for the mixture (air + particles), and the modified $k-\epsilon$ model.

\section{Air-mass conservation is}

$$
\frac{\partial \rho}{\partial t}+\frac{\partial \rho u_{i}}{\partial x_{i}}=0
$$

Particle-mass conservation in suspension layer is

$$
\frac{\partial \bar{C}}{\partial t}+\frac{\partial \bar{C}\left(u_{i}-U_{\mathrm{F}_{\mathrm{i}}}\right)}{\partial x_{i}}=\frac{\partial}{\partial x_{i}}\left(\frac{v_{t}}{\sigma_{\mathrm{s}}} \frac{\partial \bar{C}}{\partial x_{i}}\right)+\vec{e}_{\mathrm{i}} \iint_{S_{\mathrm{sol}}} \varphi_{\mathrm{s}} \vec{n} \mathrm{~d} S .
$$

Particle-mass conservation in the saltation layer is

$$
\frac{\partial \bar{C}_{\mathrm{s}}}{\partial t}+\frac{\partial \bar{C}_{\mathrm{s}} u_{i}}{\partial x_{i}}=\vec{e}_{i} \iint_{S_{\text {salt. }}}\left(\varphi_{g}+\varphi_{\mathrm{s}}\right) \vec{n} \mathrm{~d} S
$$

Momentum conservation is

$$
\begin{aligned}
\frac{\partial\left(\rho_{\mathrm{m}} u_{i}\right)}{\partial t} & +\frac{\partial\left(\rho_{\mathrm{m}} u_{i} u_{j}\right)}{\partial x_{j}}+\frac{\partial p}{\partial x_{i}}=\sigma \bar{C} g_{i} \\
& +\frac{\partial}{\partial x_{j}}\left(\frac{v_{\mathrm{t}}}{\sigma_{\mathrm{s}}} \frac{\partial \rho_{\mathrm{m}} u_{i}}{\partial x_{j}}\right)-u_{i} \vec{e}_{i} \iint_{S_{\mathrm{sol}}} \varphi_{\mathrm{g}} \vec{n} \mathrm{~d} S
\end{aligned}
$$


Turbulent kinetic energy conservation is

$$
\frac{\partial k}{\partial t}+\overline{u_{i}} \frac{\partial k}{\partial x_{i}}=\frac{\partial}{\partial x_{i}}\left[\frac{v_{\mathrm{t}}}{\sigma_{k}} \frac{\partial k}{\partial x_{i}}\right]-\overline{u_{i}^{\prime} u_{j}^{\prime}} \frac{\partial \overline{u_{i}}}{\partial x_{j}}-\epsilon+S_{k} .
$$

Turbulent kinetic-energy dissipation conservation is

$\frac{\partial \epsilon}{\partial t}+\overline{u_{i}} \frac{\partial \epsilon}{\partial x_{i}}=\frac{\partial}{\partial x_{i}}\left[\frac{v_{\mathrm{t}}}{\sigma_{\epsilon}} \frac{\partial \epsilon}{\partial x_{i}}\right]-C_{1 \epsilon} \frac{\epsilon}{k} \overline{u_{i}^{\prime} u_{j}^{\prime}} \frac{\partial \overline{u_{i}}}{\partial x_{j}}-C_{2 \epsilon} \frac{\epsilon^{2}}{k}+S_{\epsilon}$

where

$$
\begin{aligned}
S_{k} & =-\frac{2 k}{t^{*}}\left(1-\exp \left(-\frac{t^{*} \epsilon}{2 k}\right)\right) \bar{C}, \quad S_{\epsilon}=-\frac{2 \epsilon}{t^{*}} \bar{C}, \\
t^{*} & =\frac{D_{\mathrm{p}}^{2} \sigma}{18 \mu} \quad \text { and } \quad \rho_{\mathrm{m}}=\sigma+(1-\bar{C}) \rho .
\end{aligned}
$$

$\varphi_{\mathrm{s}}$ is the mass flux exchanged between the suspension and the saltation layer. It is determined by the difference between the diffusion flux proportional to $v_{\mathrm{t}} \vec{\nabla} C$ and the settling flux which is proportional to $U_{\mathrm{F}} C$.

$\varphi_{\mathrm{g}}$ is the mass flux exchanged between the flow and the ground, determined by using the erosion or deposition flux. If $h$, the snow depth, is non-zero, and if the friction velocity $u_{*}$ at ground level is greater than the threshold friction velocity $u_{* \mathrm{t}}$, then $\varphi_{\mathrm{g}}$ is equal to the erosion flux. If the friction velocity $u_{*}$ at ground level is lower than the threshold friction velocity $u_{* \mathrm{t}}$, then $\varphi_{\mathrm{g}}$ is equal to the deposition flux. If the friction velocity $u_{*}$ at ground level is equal to the threshold friction velocity $u_{* t}$, then $\varphi_{\mathrm{g}}$ is equal to zero.

Changes in snow-surface level are described by the following equation:

$$
\frac{\partial h}{\partial t}=\frac{\varphi_{\mathrm{g}}}{\gamma}
$$

\section{Numerical resolution}

The complete system is solved by a Godunov numerical scheme of second-order accuracy in space and time. The resolution is obtained from a finite-element mesh. In this way, it is possible to adapt the mesh to the temporal changes of the drift. Changes in snow depth are slow. In contrast, turbulent-flow field variation is fast. Therefore, the following computation process is used: we compute the flow field until a stationary solution is reached; this velocity field allows us to compute variations in snow depth until a significant variation is observed in the deposit height. In our simulations, we consider a variation of $2 \mathrm{~mm}$ is significant (in the case of fence height $=4 \mathrm{~cm}$ ). Then the flow field is recomputed and the process is repeated along the formation of the drift.

\section{Boundary conditions}

\section{Momentum and turbulence}

The model needs a set of boundary conditions near the ground where the flow is considered to be a turbulent boundary layer defined by friction velocity and roughness. The turbulence parameters near the ground are linked to $u_{*}$ by:

$$
\begin{aligned}
& k=\sigma_{k} \frac{\left(c_{\epsilon 1}-c_{\epsilon 2}\right)}{K^{2}} u_{*}^{2}, \\
& \epsilon=\sigma_{\epsilon} \frac{\left(c_{\epsilon 1}-c_{\epsilon 2}\right)}{K^{2}} \frac{u_{*}^{3}}{K y}
\end{aligned}
$$

where: $\sigma_{k}=1, \quad \sigma_{\epsilon}=1.3, \quad c_{\epsilon 1}=1.44, \quad c_{\epsilon 2}=1.92$.

\section{Erosion flux}

First, we make the assumption that snow particles with cohesion are mainly entrained by direct aerodynamic forces. This simplification is not applicable to all cases: for example, reptation has considerable importance when cold loose snow is blown (Naaim-Bouvet, 1997). The number $N_{\mathrm{a}}$ of entrained grains per bed area unit per time unit is proportional to the excess shear stress (Anderson and Haff, 1991) : $N_{\mathrm{a}}=\zeta\left(\rho u_{*}^{2}-\rho u_{* \mathrm{t}}^{2}\right.$ where $\zeta$ is a constant $\left.N^{-1} s-1\right)$.

The erosion flux $\varphi_{\mathrm{e}}$ per area unit may be written

$$
\begin{aligned}
& \varphi_{\mathrm{e}}=N_{\mathrm{a}} V_{\mathrm{p}} \sigma, \\
& \varphi_{\mathrm{e}}=A\left(\rho u_{*}^{2}-\rho u_{*}^{2} \mathrm{t}\right) .
\end{aligned}
$$

The coefficient $A$ varies with the degree of intergranular bonding in the surface layer. The velocity profile is modified by snow transport but we have few experimental data on changes in shear velocity at the bed as a function of particle concentration. Numerical results obtained by Anderson and Haff (1991) and McEwan and Willetts (1991) are conflicting. Anderson and Haff (1991) predicted that at steady state the shear stress at the bed had fallen slightly below the threshold shear stress for aerodynamic entrainment. McEwan and Willetts (1991) predicted that at steady state the shear stress at the bed is roughly equal to its initial value. Kind (1975) assumed that the shear stress at steady state must remain at the threshold value in order to maintain the bed "mobile". We retain Kind's assumption. At first, we suggest that the friction velocity is modified. The real friction velocity near the ground $u_{* \mathrm{r}}$, which is responsible for erosion, is linked to the friction velocity by the following formula

$$
u_{* \mathrm{r}}=u_{*}+\left(u_{* \mathrm{t}}-u_{*}\right)\left(\frac{C_{\mathrm{s}}}{C_{\max }}\right)^{2} .
$$

When the particle concentration is zero, the "real" friction velocity is equal to the friction velocity. When the particle concentration reaches its highest value (steady state), the "real" friction velocity is equal to the threshold-friction velocity.

The erosion flux (Equation (14)) becomes

$$
\left.\varphi_{\mathrm{e}}=A\left(\rho\left[u_{* \mathrm{t}}-u_{*}\right)\left(\frac{C_{\mathrm{s}}}{C_{\max }}\right)^{2}+u_{*}\right]^{2}-\rho u_{* \mathrm{t}}^{2}\right)
$$

For snow particles, only the experimental data from Takeuchi (1980) are available. We chose to reproduce one of his experiments numerically in order to validate the erosion model. We considered the one referenced No.3, because in this case snowfall was limited. The snowdrifting flux reached saturation about $250 \mathrm{~m}$ downwind of the starting point. The saturated horizontal snow-mass flux, measured up to $30 \mathrm{~cm}$ above the snow surface, was approximately $20 \mathrm{~g} \mathrm{~m}^{-1} \mathrm{~s}^{-1}$. Wind speed at $1 \mathrm{~m}$ height was $7.2 \mathrm{~m} \mathrm{~s}^{-1}$. We had no information on the threshold-friction velocity and fric- 
tion velocity. We estimated these parameters from Pomeroy and Gray's (1990) semi-empirical relationships:

$$
\begin{aligned}
Q_{\mathrm{s}} & =\frac{0.68 \rho u_{* \mathrm{t}}}{g u_{*}}\left(u_{*}^{2}-u_{* \mathrm{t}}^{2}\right), \\
h_{\mathrm{s}} & =\frac{1.6 u_{*}^{2}}{2 g}, \\
C_{\max } & =\frac{\rho}{3.29 u_{*}}\left(1-\frac{u_{* \mathrm{t}}^{2}}{u_{*}^{2}}\right), \\
z_{0}{ }^{\prime} & =0.1203 \frac{u_{*}^{2}}{2 g} .
\end{aligned}
$$

We neglected the terminal fall-velocity variations with height and propose a mean value of $\sigma_{\mathrm{s}} U_{\mathrm{F}}$ estimated from the experimental data used by Mellor and Fellers(1986). In order to reproduce Takeuchi's experiment No. 3 numerically, we used the following parameters: $\sigma_{\mathrm{s}} U_{\mathrm{F}}=0.28 \mathrm{~m} \mathrm{~s}^{-1}$, $u_{*}=0.42 \mathrm{~m} \mathrm{~s}^{-1}, u_{* \mathrm{t}}=0.36 \mathrm{~m} \mathrm{~s}^{-1}$ and $C_{\max }=0.248 \mathrm{~kg} \mathrm{~m}^{-3}$. Figure 1 shows the numerical results obtained in the saltation layer and in the suspension layer, with a value of $\rho A=7 \times 10^{-4}$. Figure 2 shows the vertical variations of the concentration at different distances from the start of snow transport. These numerical results (Figs 1 and 2) are close to those of Takeuchi.

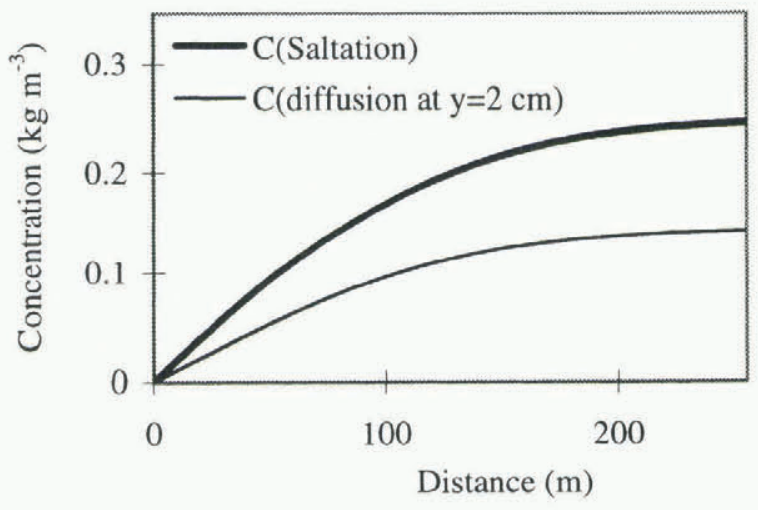

Fig. 1. Change in particle concentration in the saltation and suspension layers as a function of ablation length.

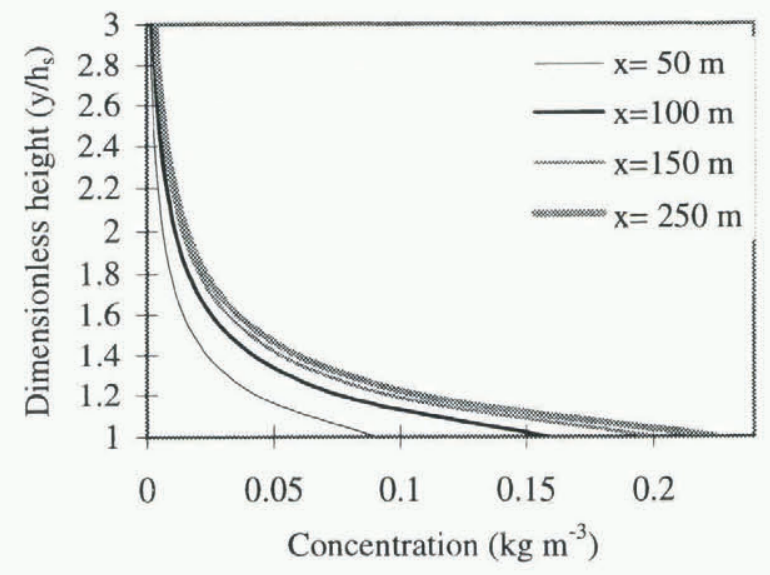

Fig. 2. Change in particle-concentration profile in the suspension layer as a function of the height at different distances from the starting point.

\section{Deposition flux}

The deposition flux is proportional to the particle-settling velocity and to the particle concentration. But it is modified by the turbulence of the flow. At $u_{*}=u_{* t}$, the deposition is equal to zero. At $u_{*}=0$, deposition occurs with its maximum value $\left(=U_{\mathrm{F}} C\right)$. The force exerted by the flow on the particle is proportional to $u_{*}^{2}$; therefore, we suggest that the deposition flux could be estimated by the following model:

$$
\phi_{\mathrm{d}}=\bar{C} U_{\mathrm{F}} \frac{\left(u_{* \mathrm{t}}^{2}-u_{*}^{2}\right)}{u_{* \mathrm{t}}^{2}} .
$$

It is essential to compare the numerical results with field experiments. But, as a first step, it is really interesting to compare the numerical results with wind-tunnel experiments where all physical processes can be measured and controlled. In this way, we can know the terminal fall velocity and the threshold friction velocity accurately and can control the friction velocity, which remains constant during the whole experiment. In our laboratory, a $13 \mathrm{~m}$ long wind tunnel has a $5 \mathrm{~m}$ test area of uniform cross-section $100 \times 50 \mathrm{~cm}$ and it is protected by a filter in order to retain the particles. The wind tunnel is equipped with a hot-film probe (one- and two-dimensional), installed on a support with three-dimensional displacement. This system allows us to measure the flow velocity and turbulence energy. A laser diode measures the height of the deposit. The measured height of the boundary layer is approximately $20 \mathrm{~cm}$. Therefore, obstacles placed in the wind tunnel must not be higher than 4-5 cm (height of the logarithm zone).

In order to test the deposition flux, the numerical simulations were performed for a $4 \mathrm{~cm}$ high solid fence with a $1 \mathrm{~cm}$ bottom gap. The models of erosion-deposition depend on: turbulent-friction velocity, threshold-friction velocity and the settling velocity.

We have therefore tested the influence of each of these factors. One supplementary test was carried out in order to evaluate the influence of the presence of particles on the turbulence model.

First, using the numerical model, with a mesh $(200 \times 200$ cells $)$, we studied the variation of the leeward and windward drifts from the beginning to steady state. We noticed that the windward and leeward drifts form simultaneously in the wind tunnel.

Next, using the numerical model, we studied (Fig. 3) the influence of $u_{*} / u_{* \mathrm{t}}$ on snowdrifts at equilibrium. We observed that the leeward drift is very sensitive to this parameter: it appears for $u_{*} / u_{* t}$ close to 1 and it disappears completely for $u_{*} / u_{* \mathrm{t}}>1.2$. This could explain the difficulties in reproducing leeward drift in a wind tunnel (Naaim-Bouvet, 1997). The windward drift is less sensitive; the accumulated

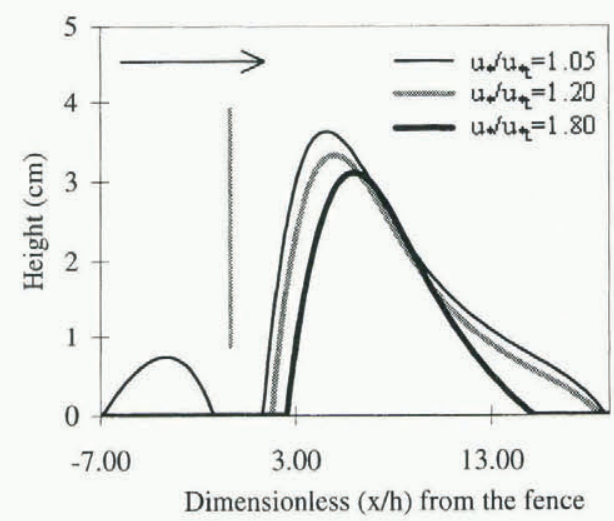

Fig. 3. Variation of equilibrium drift shape as function of $u_{*} / u_{* \mathrm{t}}$. 
volume increases as $u_{*} / u_{* t}$ decreases, as previously observed in a wind tunnel for the drift of sawdust generated by a solid fence (height $H$ ) with a bottom gap $(0.2 H)$ (Naaim-Bouvet, 1997) (Fig. 4).

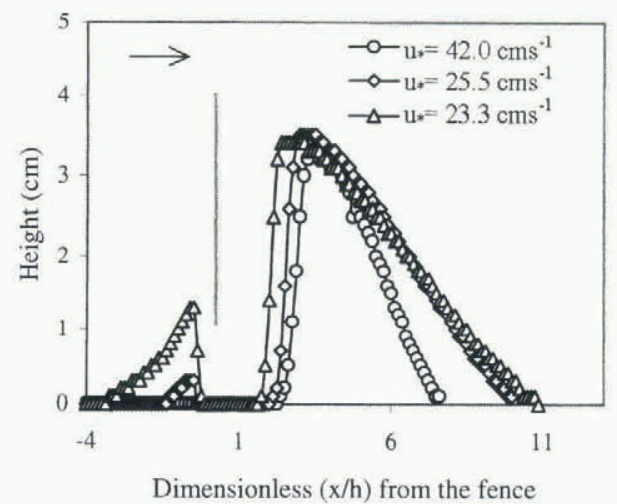

Fig. 4. Experimental results obtained in a wind lunnel for different friction velocities.

The settling velocity does not affect the final profile of the drift. But the formation time depends on this parameter. The snowdrift forms rapidly if the settling velocity is important. In Figure 5, we show two snowdrifts formed in $30 \mathrm{~min}$ utes at two different settling velocities.

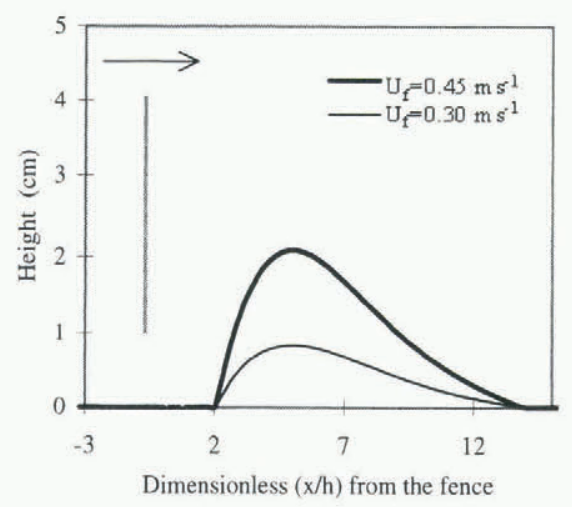

Fig. 5. Drift obtained for two different settling velocities in 30 minutes.

We have tested two turbulence models, the classical $k-\epsilon$ model and the modified $k-\epsilon$ model proposed by Chen and Wood (1985), taking into account the influence of the particles (Fig. 6).

The difference between results obtained using the two models is very small. For the same initial conditions, the snowdrift generated by the modified $k-\epsilon$ model is slightly more extended than that generated by the $k-\epsilon$ model. Indeed, in the modified $k-\epsilon$ model, the presence of particles produces a diminution in the friction velocity near the ground. The zone covered by the deposit $\left(u_{*}<u_{* \mathrm{t}}\right)$ is therefore larger than that obtained by the classic $k-\epsilon$ model.

Finally (Figs 7 and 8), we have reproduced numerically some experiments obtained using a wind tunnel. In the two cases presented, the shapes of the numerical snowdrifts and the experimental snowdrifts are relatively similar. In the case of numerical simulation, the leeward snowdrift is less important. Near the fence, the experimental leeward and

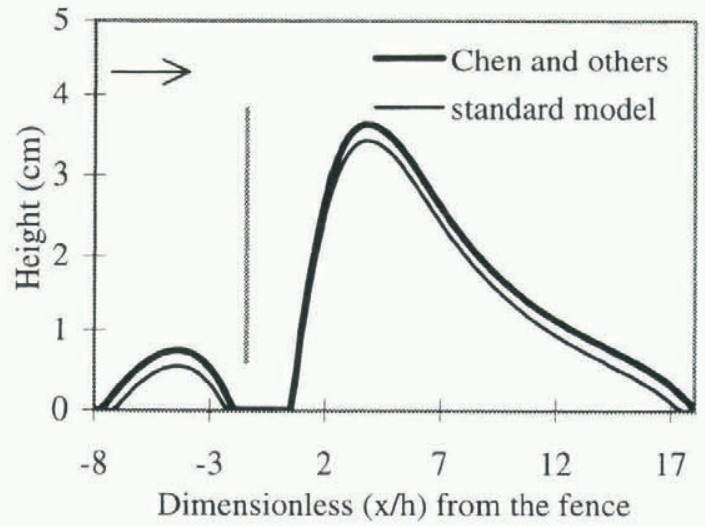

Fig. 6. Test of the two turbulence models for $\left(u_{*} / u_{* \mathrm{t}}\right)=1.05$.

windward snowdrifts are steeper than those obtained numerically. We can attribute this phenomenon to numerical diffusion and also to the inadequate mesh in the highslope zones. The mesh is very deformed in these zones. The solution should be using a mesh orthogonal to the drift in order to reduce the numerical diffusion.

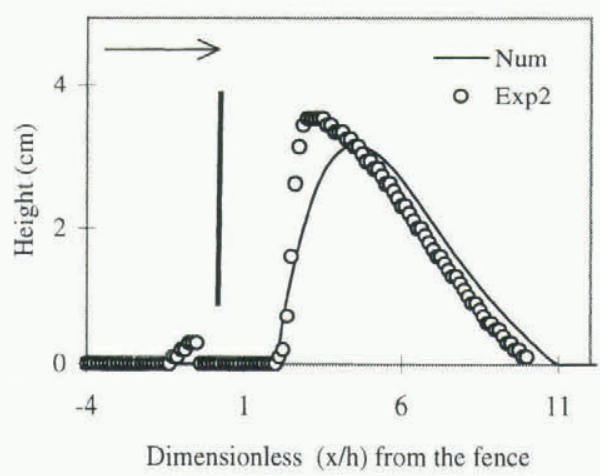

Fig. 7. Comparison between numerical and experimental results $\left(u_{*}=0.25 \mathrm{~ms}^{-1}\right.$ and $\left.u_{* \mathrm{t}}=0.21 \mathrm{~ms}^{-1}\right)$.

The windward snowdrift localization is well reproduced by the model. In the case of $u_{*}=0.25 \mathrm{~m} \mathrm{~s}^{-1}$ and $u_{* \mathrm{t}}=$ $0.21 \mathrm{~m} \mathrm{~s}^{-1}$, the numerical snowdrift begins at the same place. In the case of $u_{*}=0.23 \mathrm{~m} \mathrm{~s}^{-1}$ and $u_{* \mathrm{t}}=0.21 \mathrm{~m} \mathrm{~s}^{-1}$, it begins slightly upstream. Numerical and experimental snowdrift lengths are very close. In the case of $u_{*}=0.25 \mathrm{~m} \mathrm{~s}^{-1}$ and $u_{* \mathrm{t}}=0.21 \mathrm{~m} \mathrm{~s}^{-1}$, the numerical snowdrift is longer than the

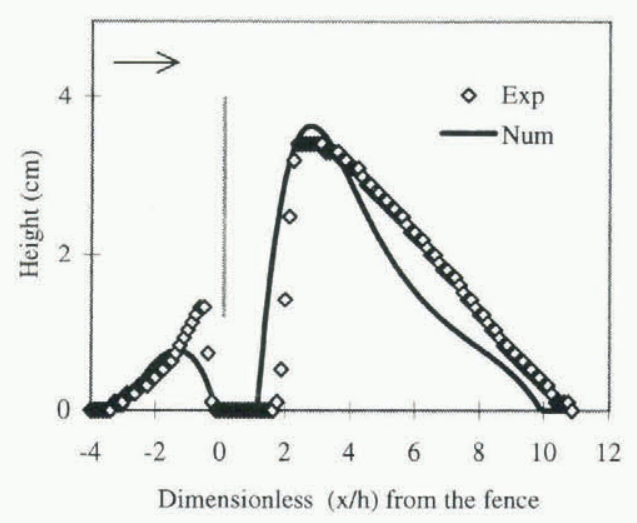

Fig. 8. Comparison between numerical and experimental results $\left(u_{*}=0.23 \mathrm{~m} \mathrm{~s}^{-1}\right.$ and $\left.u_{* \mathrm{t}}=0.21 \mathrm{~ms}^{-1}\right)$. 
experimental one but in the case of $u_{*}=0.23 \mathrm{~m} \mathrm{~s}^{-1}$ and $u_{* \mathrm{t}}=0.21 \mathrm{~m} \mathrm{~s}^{-1}$ it is shorter.

\section{GONCLUDING REMARKS}

In this paper, assumptions and preliminary results of a numerical model of snowdrift are presented. This model is based on continuum theory and erosion and deposition fluxes. It provides numerical results that are in good agreement with observed data taken around a snow fence. Variations in snowdrift formation are correctly simulated. We tested the model in the case of a $4 \mathrm{~cm}$ high fence with a $1 \mathrm{~cm}$ high gap. Unlike the windward accumulation, the leeward accumulation is very sensitive to the ratio $\left(u_{*} / u_{* \mathrm{t}}\right)$. It appears for $\left(u_{*} / u_{* \mathrm{t}}\right)$ close to 1 and disappears for $\left.\left(u_{*} / u_{* \mathrm{t}}\right)>1.2\right)$. The global accumulation produced by the fence increases as $\left(u_{*} / u_{* t}\right)$ decreases. The back reaction of particles on turbulence slightly extends the windward accumulation. In spite of these good results, expression of the erosion flux must be re-examined in order to improve it. It will be necessary to carry on with experiments similar to those undertaken by Takeuchi (1980) or to determine the splash function for different snow qualities.

\section{REFERENCES}

Anderson, R. S. and P. K. Haff. 1991. Wind modification and bed response during saltation of sand in air. Acta Mech., Supplementum 1. Aeolian
Grain Transport. 1: Mechanics, 21-52.

Chen, C. P. and P. E. Wood. 1985. A turbulence closure model for dilute gas particle flows. Can. 7. Chem. Eng., 63(3), 349-360.

Kind, R. J. 1975. A critical examination of the requirements for model simulation of wind-induced erosion/deposition phenomena such as snow drifting. Atmos. Environ., 10, 219-227.

Liston, G. E., R. L. Brown and J. D. Dent. 1993. A two-dimensional computational model of turbulent atmospheric surface flows with drifting snow. Ann. Glaciol., 18, 281-286.

Liston, G. E., R. L. Brown and J. D. Dent. 1994. A computational model of two-phase, turbulent atmospheric boundary layer with blowing snow. In Workshop on Modeling of Windblow Snow and Sand, 1994, Snowbird, Utah. Papers.

McEwan, I. K. and B. B. Willetts. 1991. Numerical model of the saltation cloud. Acta Mech., Supplementum 1. Acolian Grain Transport. 1: Mechanics, 53-66.

Mellor, M. and G. Fellers. 1986. Concentration and flux of wind-blown snow. CRREL Spec. Rep. 86-11.

Naaim, M. and H. Martinez. 1995. Experimental and theoretical determination of concentration profiles and influence of particle characteristics in blowing snow. Surv. Geophys, 16(5-6), 695-710.

Naaim-Bouvet, F. 1997. Contribution à la modélisation physique et numérique du transport de neige par le vent. (Thèse de doctorat, Université de Grenoble.)

Pomeroy, J.W. and D. M. Gray. 1990. Saltation of snow. Water Resour. Res., 26 (7), 1583-1594.

Takeuchi, M. 1980. Vertical profile and horizontal increase of drift-snow transport. J. Glaciol., 26 (94), 481-492.

Uematsu, T., Y. Kaneda, K. Takeuchi, T. Nakata and M. Yukumi. 1989. Numerical simulation of snowdrift development. Ann. Glaciol., 13, 265-268.

Uematsu, T., T. Nakata, K. Takeuchi, Y. Arisawa and Y. Kaneda. 1991. Three-dimensional numerical simulation of snowdrift. Cold Reg. Sci. Technol., 20 (1), 65-73. 